\title{
Coronary artery bypass grafting versus stent implantation in patients with chronic coronary syndrome and left main disease: insights from a register throughout Germany
}

\author{
Peter Stachon ${ }^{1,2}$ D $\cdot$ Klaus Kaier ${ }^{2,3} \cdot$ Philip Hehn $^{2,3} \cdot$ Alexander Peikert $^{1} \cdot$ Dennis Wolf ${ }^{1} \cdot$ Vera Oettinger $^{1,2}$. \\ Dawid Staudacher ${ }^{1}$ - Daniel Duerschmied ${ }^{1} \cdot$ Andreas Zirlik $^{4} \cdot$ Manfred Zehender $^{1,2} \cdot$ Christoph Bode $^{1}$. \\ Constantin von zur Mühlen ${ }^{1,2}$
}

Received: 8 June 2021 / Accepted: 17 August 2021 / Published online: 28 August 2021

(C) The Author(s) 2021

\begin{abstract}
Background Recent randomized controlled trials have sparked debate about the optimal treatment of patients suffering from left main coronary artery disease. The present study analyzes outcomes of left main stenting versus coronary bypass grafting $(\mathrm{CABG})$ in a nationwide registry in patients with chronic coronary syndrome (CCS).

Methods All cases suffering from CCS and left main coronary artery disease treated either with CABG or stent, were identified within the database of the German bureau of statistics. Logistic or linear regression models were used with 20 baseline patient characteristics as potential confounders to compare both regimens.

Results In 2018, 1318 cases with left main stenosis were treated with CABG and 8,920 with stent. Patients assigned for stenting were older $(72.58 \pm 9.87$ vs. $68.63 \pm 9.40, p<0.001)$ and at higher operative risk, as assessed by logistic EuroSCORE $(8.77 \pm 8.45$ vs. $4.85 \pm 4.65, p<0.001)$. After risk adjustment, no marked differences in outcomes were found for in-hospital mortality and stroke (risk adjusted odds ratio (aOR) for stent instead of CABG: aOR mortality: 1.08 [95\% CI 0.66; 1.78], $p=0.748$; aOR stroke: 0.59 [0.27; 1.32], $p=0.199)$. Stent implantation was associated with a reduced risk of relevant bleeding (aOR 0.38 [0.24; 0.61], $p<0.001$ ), reduced prolonged ventilation time (aOR 0.54 [0.37 0.79], $p=0.002$ ), and postoperative delirium (aOR $0.16[0.11 ; 0.22], p<0.001)$. Furthermore, stent implantation was associated with shorter hospital stay $(-6.78$ days $[-5.86 ;-7.71], p<0.001)$ and lower costs $(-€ 10,035[-€ 11,500 ;-€ 8570], p<0.001)$.

Conclusion Left main stenting is a safe and effective treatment option for CCS-patients suffering from left main coronary artery disease at reasonable economic cost.
\end{abstract}

Peter Stachon

Peter.stachon@universitaets-herzzentrum.de

1 Department of Cardiology and Angiology I, University

Heart Center Freiburg-Bad Krozingen, Faculty of Medicine,

University of Freiburg, Freiburg, Germany

2 Center of Big Data Analysis in Cardiology (CeBAC), Department of Cardiology and Angiology I, University Heart Center Freiburg-Bad Krozingen, Faculty of Medicine, University of Freiburg, Freiburg, Germany

3 Institute of Medical Biometry and Statistics, Faculty of Medicine and Medical Center, University of Freiburg, Freiburg, Germany

4 Department of Cardiology, University Hospital Graz, Graz, Austria 


\section{Graphic abstract}

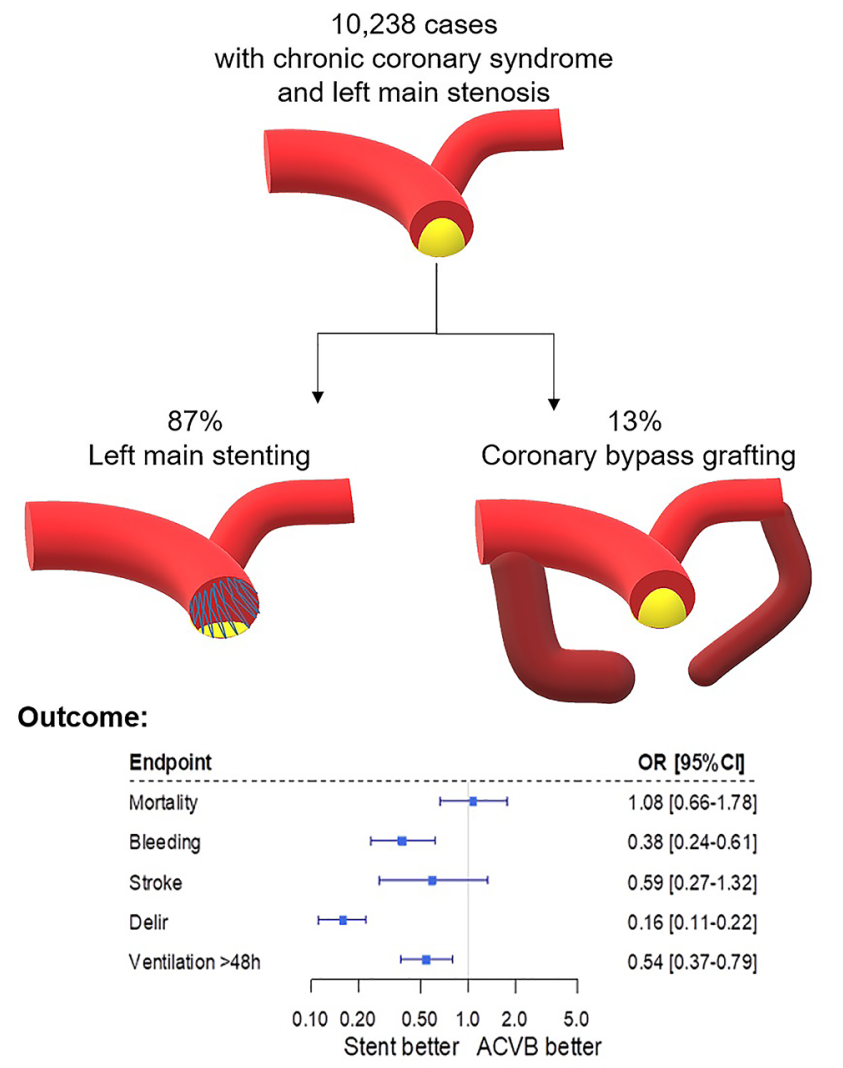

Coronary artery bypass grafting versus stent implantation in patients with chronic coronary syndrome and left main disease: insights from a register throughout Germany. All cases with chronic coronary syndrome and left main stenosis treated in 2018 in Germany either with left main stenting or coronary bypass grafting were extracted from a nation-wide database. In-hospital outcomes were compared after logistic regression analysis.

Keywords Left main coronary artery disease $\cdot$ Stent $\cdot$ Coronary artery bypass grafting $\cdot$ mortality

\section{Introduction}

About $5 \%$ of patients with chronic coronary syndrome (CCS) and $7 \%$ of patients with acute myocardial infarction suffer from left main disease [9]. The left main coronary artery accounts for about $75 \%$ of the blood supply of the left ventricle [10]. Consequently, 3-year mortality of left main stenosis is nearly $50 \%$ in patients receiving medical treatment only [9]. Studies from the $80 \mathrm{~s}$ and $90 \mathrm{~s}$ showed improved survival in patients undergoing surgical revascularization by $\mathrm{CABG}$, with a risk reduction of about $70 \%$ $[1,18,27,28]$. Thus CABG became the standard of care for patients with left main stenosis. However, there was still significant CABG related morbidity and mortality [8]. In 1986 the first coronary stent was implanted. This was a breakthrough for interventional cardiology, since it overcame the weakness of pure balloon angioplasty in particular in left main stenosis [7, 21]. Further innovations and increasing experience in the field of coronary interventions led to the consideration in the last decades whether the less invasive left main stenting may be an alternative to $\mathrm{CABG}$.

Five randomized controlled trials have been conducted with a long-term follow-up ranging from 5 to 10 years [2, $5,12,14,15,17,23,24,26]$. A meta-analysis summarizing those studies found no differences in all-cause mortality, cardiac death, stroke, or myocardial infarction between CABG and percutaneous coronary intervention (PCI) [2]. However, the risk of unplanned revascularization is consistently higher in patients treated with PCI in all studies.

Consequently, the guidelines have implemented those results into their recommendations: PCI and CABG are rated as equivalent by the European Society of Cardiology, with an IA recommendation in patients with morphological low risk stenosis (SYNTAX 0-22). With more morphologically complex stenosis, the recommendations favor CABG [16]. 
The present study investigates the decision making towards CABG or PCI in patients suffering from left main stenosis in clinical practice by analyzing a complete national dataset. We compare in-hospital death and further complications such as bleeding, stroke, postoperative delirium, and prolonged ventilation between both treatment options. Furthermore, the resource utilization is determined.

\section{Methods}

Since 2005, data on all hospitalizations in Germany have been available for scientific use via the Diagnosis Related Groups statistics collected by the Research Data Center of the Federal Bureau of Statistics (DESTATIS). These hospitalization data, including diagnoses and procedures, are a valuable source of representative nationwide data on the in-hospital treatment of patients. This database represents a virtually complete collection of all hospitalizations in German hospitals that are reimbursed according to the Diagnosis Related Groups system. From this database, we extracted data on patients with left main stenosis (I25.14) who underwent either isolated CABG or coronary stent implantation in 2018, the most recent available year for analysis. In order to identify comparable groups, patients with acute coronary syndromes such as in-stent stenosis, NSTEMI, STEMI or unstable angina pectoris were excluded from the dataset. Emergency admission are coded whenever patients are admitted non-elective via ambulance or emergency department. Furthermore, patients with any other kind of concomitant heart valve surgery during the same episode of hospitalization were also excluded. A complete list of procedure codes as well as a more detailed discussion of the validity of the data source may be found in Table S1.

Our study did not involve direct access by the investigators to data on individual patients but only access to summary results provided by the Research Data Center. Therefore, approval by an ethics committee and informed consent were determined not to be required, in accordance with German law.

All summary results were anonymized by DESTATIS. In practice, this means that any information allowing the drawing of conclusions about a single patient or a specific hospital was censored by DESTATIS to guarantee data protection. Moreover, in order to prevent the possibility to draw conclusions to a single hospital, the data are verified and situationally censored by DESTATIS in those cases.

\section{Endpoints}

The analysis focused on seven different endpoints: in-hospital mortality, bleeding events, stroke, postoperative delirium, mechanical ventilation exceeding $48 \mathrm{~h}$, length of hospital stay and reimbursement. Stroke and postoperative delirium were defined using ICD, tenth revision (ICD-10) codes (secondary diagnosis I63* or I64 and F05*, respectively). Bleeding was defined as requiring a transfusion of $>5$ units of red blood cells and identified using OPS-codes (8-800. c1 to 8-800.cr). In-hospital mortality, length of mechanical ventilation, and length of hospital stay were part of DESTATIS' main set of variables. For all other comorbidities, the existing anamnestic or acute distinctive codes were used (we have discussed OPS and ICD codes in detail previously ${ }^{8}$ ).

For calculation of the estimated logistic EuroSCORE (European System for Cardiac Operative Risk Evaluation), we were able to populate all fields except for critical preoperative state and left ventricular function. In these, we assumed an inconspicuous state (i.e., no critical preoperative state and no left ventricular dysfunction) and thus calculated a best-case scenario.

\section{Statistical analysis}

In previous studies [20,22], we identified 20 baseline characteristics to describe risk profiles between procedural groups. Patients were treated in clinical practice and not randomized to the two treatment options (CABG or coronary stent implantation). Therefore a logistic or linear regression model were used including 20 baseline patient characteristics as potential confounders (Table 1). Nonelective emergency admission of the procedure was also added as confounder. To account for the correlation of error terms of patients treated in the same hospital, a random intercept was included at the center level. See Table S2 for results of the different regression analyses.

No imputation for missing values could be conducted due to the absence of codes indicating that data were missing. If the patient's electronic health record did not include information on a clinical characteristic, it was assumed that that characteristic was not present. Furthermore, no adjustment for multiple testing was carried out. Thus, $p$ values may not be interpreted as confirmatory but are descriptive in nature and inferences drawn from the $95 \%$ confidence intervals may not be reproducible.

All analyses were performed with Stata 16 (StataCorp, College Station, Texas, USA).

\section{Results}

\section{Treatment decision in clinical practice in 2018}

All 10,238 cases with diagnosis of left main stenosis receiving either CABG or stent in Germany 2018 were identified. Patients with STEMI, NSTEMI, unstable angina, in-stent stenosis, and any kind of concomitant 
Table 1 Baseline characteristics 2018

\begin{tabular}{lllr}
\hline & CABG & Stent & $p$ value \\
\hline$N$ & 1318 & 8920 & \\
Logistic EuroSCORE ${ }^{1}$, mean/ & $4.85 \pm 4.65$ & $8.77 \pm 8.45$ & $<0.001$ \\
SD & & & \\
Age in years, mean/SD & $68.63 \pm 9.40$ & $72.58 \pm 9.87$ & $<0.001$ \\
Female \% & $16.24 \%$ & $22.05 \%$ & $<0.001$ \\
NYHA II, \% & $<0.30 \% *$ & $11.63 \%$ & $<0.001$ \\
NYHA III or IV, \% & $23.60 \%$ & $16.69 \%$ & $<0.001$ \\
Hypertension, \% & $74.81 \%$ & $63.91 \%$ & $<0.001$ \\
Previous MI within 4 months, & $2.50 \%$ & $5.78 \%$ & $<0.001$ \\
$\quad \%$ & & & \\
Previous MI within 1 year, $\%$ & $1.59 \%$ & $2.57 \%$ & 0.032 \\
Previous MI after 1 year, \% & $<0.30 \% *$ & $10.01 \%$ & $<0.001$ \\
Previous CABG, \% & $<0.30 \% *$ & $16.14 \%$ & $<0.001$ \\
Previous cardiac surgery, $\%$ & $<0.30 \% *$ & $18.06 \%$ & $<0.001$ \\
Peripheral vascular disease, \% & $10.24 \%$ & $8.17 \%$ & $<0.001$ \\
Carotid disease, \% & $<0.30 \% *$ & $3.11 \%$ & $<0.001$ \\
COPD, \% & $<0.30 \% *$ & $7.59 \%$ & $<0.001$ \\
Pulmonary hypertension & $<0.30 \% *$ & $5.62 \%$ & $<0.001$ \\
Renal disease, GFR <15\%, \% & $<0.30 \% *$ & $1.74 \%$ & $<0.001$ \\
Renal disease, GFR <30\%, \% & $<0.30 \% *$ & $2.22 \%$ & $<0.001$ \\
Atrial fibrillation, \% & $33.16 \%$ & $21.61 \%$ & $<0.001$ \\
Diabetes, \% & $32.32 \%$ & $32.43 \%$ & 0.936 \\
Emergency Admission & $<0.30 \% *$ & $25.81 \%$ & $<0.001$ \\
\hline
\end{tabular}

$S D$ standard deviation, NYHA New York Heart Association class, $M I$ myocardial infarction, $C A B G$ coronary artery bypass grafting, $C O P D$ chronic obstructive pulmonary disease, $G F R$ glomerular filtration rate

*Groups with $<3$ cases are blanked out by the Research Data Centers of the Federal Bureau of Statistics for reasons of anonymity. Thus, the share of those patients is under $0.3 \%{ }^{1}$ For calculation of the estimated logistic EuroSCORE (European System for Cardiac Operative Risk Evaluation), we were able to populate all fields except for critical preoperative state and left ventricular function. In these, we assumed an inconspicuous state (i.e., no critical preoperative state and no left ventricular dysfunction) and thus calculated a best-case scenario.

heart valve surgery were excluded. $87 \%$ of patients with chronic coronary syndrome and left main coronary artery disease were assigned to stent implantation (Fig. 1).

\section{Baseline characteristics}

The stent group was older, had more relevant comorbidities such as coronary, carotid, or peripheral artery disease, and renal or pulmonary disease. Moreover, cases assigned to stent were more often admitted as emergency cases, but CABG patients were more frequently in NYHA class III or IV. The share of female patients was $16 \%$ in the CABG group and $22 \%$ in the stent group. In summary, the stent group was at higher operative risk as assessed

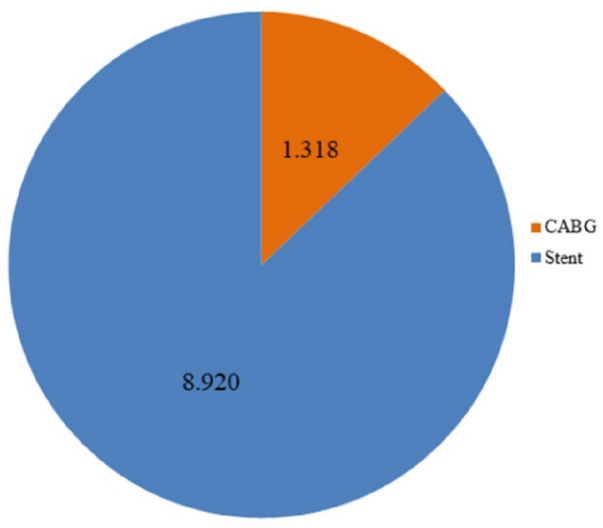

Fig. 1 CABG vs. stent distribution in clinical practice in 2018. All cases with diagnosis of left main stenosis without STEMI, NSTEMI, unstable angina, in-stent stenosis, and without any other concomitant heart valve surgery were identified

by the logistic EuroSCORE $(4.85 \pm 4.65$ vs. $8.77 \pm 8.45$, $p<0.001$, Table 1 ).

\section{Unadjusted in-hospital outcomes}

The in-hospital mortality of patients after CABG was $1.7 \%$ and after stent $2.4 \%$ in patients with left main disease $(p=0.109)$. Relevant bleedings occurred in $4.8 \%$ of patients after CABG and $2.4 \%$ of patients after stent $(p<0.001)$. The rate of stroke was $0.83 \%$ in the $\mathrm{CABG}$ group and $0.45 \%$ in the stent group $(\mathrm{p}<0.001)$. Naturally, postoperative delirium $(9.0 \%$ vs. $1.9 \%, p<0.001)$ and prolonged mechanical ventilation $(4.7 \%$ vs. $2.1 \%, p<0.001)$ were more frequently observed in the CABG group (Table 2).

\section{Multivariable analysis of in-hospital outcomes}

After adjusting for all baseline characteristics, risk for inhospital mortality (OR 1.08, [95\% CI 0.66; 1.78], $p=0.748$ ) and stroke (OR 0.56 [0.27; 1.32], $p=0.199$ ) did not differ between $\mathrm{CABG}$ and stent in patients suffering from left main disease and chronic coronary syndrome. According to the results of the unadjusted analysis, the risk of other complications was higher in the CABG group. Stent implantation was

Table 2 Unadjusted in-hospital outcomes 2018

\begin{tabular}{lllr}
\hline & CABG & Stent & \multicolumn{1}{c}{$p$ value } \\
\hline$N$ & 1318 & 8920 & 0.109 \\
In-hospital mortality & $1.67 \%$ & $2.38 \%$ & $<0.001$ \\
Bleeding & $4.78 \%$ & $1.17 \%$ & 0.063 \\
Stroke & $0.83 \%$ & $0.45 \%$ & $<0.001$ \\
Postoperative delirium & $9.03 \%$ & $1.91 \%$ & $<0.001$ \\
Mechanical ventilation $>48 \mathrm{~h}$ & $4.70 \%$ & $2.09 \%$ & $<0.001$ \\
\hline
\end{tabular}




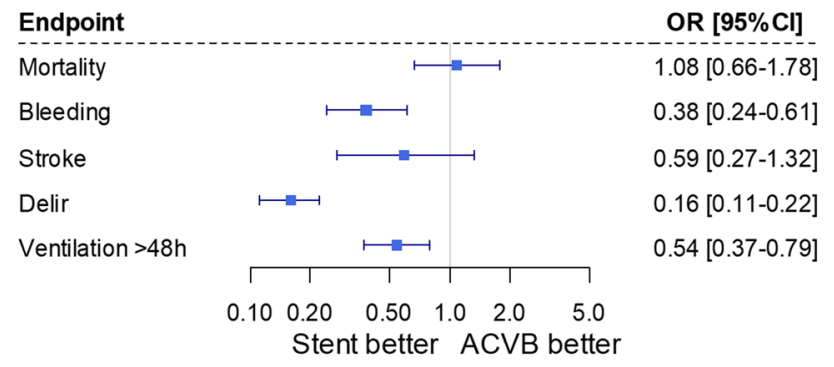

Fig. 2 Risk-adjusted in-hospital outcomes. Results of multivariable logistic regression analyses with predefined baseline patient characteristics included as potential confounders (all covariates listed in Table 1)

associated with significantly reduced risk for relevant bleeding (OR 0.38 [0.24; 0.61], $p<0.001)$, prolonged ventilation time (OR 0.54 [0.37;0.79], $p=0.002$ ), and postoperative delirium (OR $0.16[0.11 ; 0.22], p<0.001$, Fig. 2).

\section{Resource utilization CABG vs. stent}

Naturally the invasiveness is usually higher in CABG than in left main stenting. In order to elucidate the resource utilization of both treatment options we determined length of hospital stay and reimbursement. Patients undergoing CABG were hospitalized 7.3 days longer (CABG 13.04 \pm 9.26 , stent $5.71 \pm 7.60$ days, $p<0.001)$. Accordingly, the costs of CABG were three times higher than those of left main stenting (CABG: 17,573.78 $\pm 11,153.57 €$; stent: $5892.94 \pm 8695.00 €$, $p<0.001)$. Even after adjusting for risk factors, PCI was associated with shorter hospital stay $(-6.78$ days $[-5.86$; $-7.71], p<0.001)$ and lower costs $(-10,035 €[-11,500$; $-8570], p<0.001)$. Thus, the resource utilization is lower in patients with left main stenosis undergoing left main stenting (Table 3).

\section{Discussion}

The present study including 10,238 cases shows that in-hospital mortality was not significantly different between PCI and $\mathrm{CABG}$ in patients with left main coronary artery disease in clinical practice. It also shows that the vast majority of patients with left main stenosis underwent stenting. Patients assigned for left main stenting had lower risk for in-hospital complications such as bleeding, prolonged mechanical ventilation, and postoperative delirium. PCI utilized less healtheconomic resources.

The ESC guidelines rank left main stenting as equal to CABG for patients with stable coronary artery disease and low SYNTAX score, with an IA recommendation for both [16]. The American revascularization guidelines rate left main PCI as an appropriate alternative to CABG in patients with low-to-intermediate anatomical complexity [19]. The present analysis shows that left main stenting is the main treatment approach in current clinical practice in Germany. In 2018 almost $90 \%$ of patients with chronic coronary syndrome were assigned for left main stenting, indicating the importance of PCI in the care of patients suffering from left main stenosis in clinical practice.

The decision making for PCI vs. CABG should be made by an interdisciplinary approach within the Heart Team to provide an individualized treatment concept. Anatomical and technical aspects, patient's preferences, and clinical characteristics such as age and comorbidities should be considered [16]. In the present cohort, the patients assigned for left main stenting were older, had more comorbidities, and consequently a higher logistic EuroSCORE. This might account for the high proportion of stenting in clinical practice.

Randomized clinical trials provide evidence for clinical guidelines. However, patients are carefully selected before participation. Thus, marked differences occur between clinical trials and daily practice. Therefore the present data-set is a reliable tool to assess guideline adherence and outcomes in clinical practice, although long-term follow-up data is not available [20,22]. Without adjustment we found slightly increased in-hospital mortality after PCI. With respect to the increased operative risk in patients undergoing PCI, we performed a multivariate logistic regression to allow a comparison of both treatment strategies and found that after risk adjustment the risk for death did not differ. This is in line with data from the NOBLE, EXCEL, PRECOMBAT, and SYNTAX

Table 3 Ressource utilization

\begin{tabular}{|c|c|c|c|}
\hline & \multicolumn{2}{|l|}{ Unadjusted } & \multirow{2}{*}{$\begin{array}{l}\text { Adjusted } \\
\text { Stent instead of CABG } \\
\text { Coefficient }[95 \% \mathrm{CI}]\end{array}$} \\
\hline & CABG & Stent & \\
\hline $\begin{array}{l}\text { Length of } \\
\text { hospital } \\
\text { stay in days }\end{array}$ & $13.04 \pm 9.26$ & $5.71 \pm 7.60$ & $-6.78[-5.86$ to -7.71$] p<0.001$ \\
\hline $\begin{array}{l}\text { Reimburse- } \\
\text { ment in } \\
\text { Euro }\end{array}$ & $17,573.78 \pm 11,153.57$ & $5892.94 \pm 8695.00$ & $-10,035[-11,500$ to -8570$] p<0.001$ \\
\hline
\end{tabular}


trials, where short-term and long-term mortality was similar in patients suitable for both CABG and left main stenting $[2,14,17,26]$. In a meta-analysis summarizing these trials, mortality did not differ even after long-term follow-up of up to 10 years [2]. The present analysis confirms that the results of randomized trial are translated into the clinical practice: in-hospital mortality of PCI and $\mathrm{CABG}$ in patients with CCS and left main stenosis are comparable. Accordingly, risk for stroke also did not significantly differ in randomized trials and in the present analysis. However, we could analyze outcomes which are not reflected in the randomized controlled trials. Due to the more invasive nature of $\mathrm{CABG}$ it is not surprising that the risk for relevant bleeding, prolonged ventilation, and postoperative delirium was higher in the CABG group. Those factors increase the utilization of hospital resources such as stay on intensive care unit. In particular during the COVID pandemic this may be an important benefit of left main stenting compared to CABG [3, 4]. Although those complications did not result in increased in-hospital mortality, they may be associated with long-term sequelae: blood transfusion can cause transfusion reactions [25], mechanical ventilation can result in ventilator-associated pneumonia [13], and postoperative delirium may induce or accelerate long-term cognitive decline [11]. The risk for repeated revascularization was consistently increased for patients undergoing left main stenting in all clinical trials during the follow-up period. Due to the nature of the present data set, we analyzed only in-hospital outcomes. Thus, we cannot report whether the observed reduction of in-hospital complications in patients undergoing left main stenting outweigh repeated revascularization during follow-up as seen in randomized controlled trials. Nevertheless, integrating results of randomized controlled trial with the present analysis shows that left main stenting is safe with even some advantages in respect to in-hospital complications in clinical practice beyond clinical trials. Convincing results in clinical practice and positive results clinical trials might explain why left main stenting markedly overtook CABG compared to guidelines recommendations.

Considering the comparable outcomes with respect to mortality and other complications, we analyzed the resource utilization of CABG vs. stent in patients with left main stenosis. Unsurprisingly given the less invasive approach of stenting and lower rate of in-hospital complications, the length of hospital stay was shorter by 7.3 days. Costs per case were over 11,000 Euro lower in the PCI group. This is in line with analyses of the SYNTAX study where left main stent was associated with more favorable costs in particular in low-risk patients [6]. The economic aspects become more important advanced treatment strategies which are associated with increased costs.

\section{Limitations}

In our study, we analyze a special subset of patients: those with CCS and a left main stenosis, but without concomitant indications for surgery of valvular disease. Therefore, we cannot transfer our findings to patients with acute coronary syndrome or three-vessel disease, or to patients with relevant other structural heart diseases.

The comparison of CABG versus stents in left main stenosis assumes that both approaches are possible. The present data source does not provide anatomical or echocardiographic data; therefore the SYNTAX score cannot be calculated. The calculated logistic EuroSCORE is an approximation since a conservative or 'best-case scenario' estimate is applied. The administrative data are designed to report diagnoses and procedures in order to trigger reimbursement. The competing interests of hospitals and health insurers ensure a high level of data reliability and quality, but coding errors cannot be completely ruled out.

In addition, long-term follow-up data are missing, as DESTATIS provides no longitudinal data or cross-links with other clinical or administrative datasets. This is of special interest with regard to repeated revascularizations, which can be more often found in patients treated with stents compared to CABG, as discussed above. Finally, this analysis relies on data from the German healthcare system and other countries' experiences may differ.

\section{Conclusion}

The present analysis shows that in CCS patients left main stenting appears the mostly used standard of care in clinical practice in Germany, with favorable in-hospital outcomes. In-hospital mortality and stroke rates are similar between the two procedures, but bleeding, postoperative delirium, and prolonged ventilation were lower in patients undergoing left main stenting compared to CABG. However, we cannot conclude on mid- and long-term outcomes of repeated revascularization in patients with PCI or CABG.

In summary, concerning in-hospital outcomes, left main stenting is a safe and essential treatment option for patients suffering from left main coronary artery disease at reasonable economic cost.

Funding Open Access funding enabled and organized by Projekt DEAL. This work was supported by the German Heart Foundation/ German Foundation of Heart Research.

Availability of data and material The dataset is available at the German Bureau of statistics. 


\section{Declarations}

Conflicts of interest All authors declare no conflicts of interest.

Ethics approval Our study did not involve direct access by the investigators to data on individual patients but only access to summary results provided by the Research Data Center. Therefore, approval by an ethics committee and informed consent were determined not to be required, in accordance with German law.

Consent for publication All authors consent to the publication. The authors hereby declare that all illustrations and figures in the manuscript are entirely original and do not require reprint permission.

Open Access This article is licensed under a Creative Commons Attribution 4.0 International License, which permits use, sharing, adaptation, distribution and reproduction in any medium or format, as long as you give appropriate credit to the original author(s) and the source, provide a link to the Creative Commons licence, and indicate if changes were made. The images or other third party material in this article are included in the article's Creative Commons licence, unless indicated otherwise in a credit line to the material. If material is not included in the article's Creative Commons licence and your intended use is not permitted by statutory regulation or exceeds the permitted use, you will need to obtain permission directly from the copyright holder. To view a copy of this licence, visit http://creativecommons.org/licenses/by/4.0/.

\section{References}

1. European Coronary Surgery Study Group (1982) Long-term results of prospective randomised study of coronary artery bypass surgery in stable angina pectoris. Lancet 2:1173-1180

2. Ahmad Y, Howard JP, Arnold AD, Cook CM, Prasad M, Ali ZA, Parikh MA, Kosmidou I, Francis DP, Moses JW, Leon MB, Kirtane AJ, Stone GW, Karmpaliotis D (2020) Mortality after drugeluting stents vs coronary artery bypass grafting for left main coronary artery disease: a meta-analysis of randomized controlled trials. Eur Heart J. https://doi.org/10.1093/eurheartj/ehaa135

3. Awad WI, Idhrees M, Kennon S, Bashir M (2020) Coronary artery bypass grafting surgery versus percutaneous coronary intervention: what is the clinical decision framework amid COVID-19 era? J Card Surg 35:2464-2466. https://doi.org/10.1111/jocs.14833

4. Benetti FJ, Awad WI, Idhrees M, Kennon S, Bashir M (2020) Coronary artery bypass grafting surgery versus percutaneous coronary intervention: what is the clinical decision framework amid COVID-19 era. J Card Surg 35:2467-2468. https://doi.org/ 10.1111 /jocs. 14832

5. Boudriot E, Thiele H, Walther T, Liebetrau C, Boeckstegers $\mathrm{P}$, Pohl T, Reichart B, Mudra H, Beier F, Gansera B, Neumann FJ, Gick M, Zietak T, Desch S, Schuler G, Mohr FW (2011) Randomized comparison of percutaneous coronary intervention with sirolimus-eluting stents versus coronary artery bypass grafting in unprotected left main stem stenosis. J Am Coll Cardiol 57:538545. https://doi.org/10.1016/j.jacc.2010.09.038

6. Cohen DJ, Osnabrugge RL, Magnuson EA, Wang K, Li H, Chinnakondepalli K, Pinto D, Abdallah MS, Vilain KA, Morice MC, Dawkins KD, Kappetein AP, Mohr FW, Serruys PW, Investigators ST (2014) Cost-effectiveness of percutaneous coronary intervention with drug-eluting stents versus bypass surgery for patients with 3-vessel or left main coronary artery disease: final results from the Synergy Between Percutaneous Coronary Intervention
With TAXUS and Cardiac Surgery (SYNTAX) trial. Circulation 130:1146-1157. https://doi.org/10.1161/circulationaha.114. 009985

7. Cohen MV, Cohn PF, Herman MV, Gorlin R (1972) Diagnosis and prognosis of main left coronary artery obstruction. Circulation 45:I57-65

8. Collet C, Capodanno D, Onuma Y, Banning A, Stone GW, Taggart DP, Sabik J, Serruys PW (2018) Left main coronary artery disease: pathophysiology, diagnosis, and treatment. Nat Rev Cardiol 15:321-331. https://doi.org/10.1038/s41569-018-0001-4

9. Conley MJ, Ely RL, Kisslo J, Lee KL, McNeer JF, Rosati RA (1978) The prognostic spectrum of left main stenosis. Circulation 57:947-952. https://doi.org/10.1161/01.cir.57.5.947

10. El-Menyar AA, Al Suwaidi J, Holmes DR Jr (2007) Left main coronary artery stenosis: state-of-the-art. Curr Probl Cardiol 32:103-193. https://doi.org/10.1016/j.cpcardiol.2006.12.002

11. Fong TG, Jones RN, Shi P, Marcantonio ER, Yap L, Rudolph JL, Yang FM, Kiely DK, Inouye SK (2009) Delirium accelerates cognitive decline in Alzheimer disease. Neurology 72:1570-1575. https://doi.org/10.1212/WNL.0b013e3181a4129a

12. Holm NR, Makikallio T, Lindsay MM, Spence MS, Erglis A, Menown IBA, Trovik T, Kellerth T, Kalinauskas G, Mogensen LJH, Nielsen PH, Niemela M, Lassen JF, Oldroyd K, Berg G, Stradins P, Walsh SJ, Graham ANJ, Endresen PC, Frobert O, Trivedi U, Anttila V, Hildick-Smith D, Thuesen L, Christiansen EH, Investigators N (2020) Percutaneous coronary angioplasty versus coronary artery bypass grafting in the treatment of unprotected left main stenosis: updated 5-year outcomes from the randomised, non-inferiority NOBLE trial. Lancet 395:191-199. https://doi.org/10.1016/S0140-6736(19)32972-1

13. Kaier K, Heister T, Motschall E, Hehn P, Bluhmki T, Wolkewitz M (2019) Impact of mechanical ventilation on the daily costs of ICU care: a systematic review and meta regression. Epidemiol Infect 147:e314. https://doi.org/10.1017/S0950268819001900

14. Makikallio T, Holm NR, Lindsay M, Spence MS, Erglis A, Menown IB, Trovik T, Eskola M, Romppanen H, Kellerth T, Ravkilde J, Jensen LO, Kalinauskas G, Linder RB, Pentikainen M, Hervold A, Banning A, Zaman A, Cotton J, Eriksen E, Margus S, Sorensen HT, Nielsen PH, Niemela M, Kervinen K, Lassen JF, Maeng M, Oldroyd K, Berg G, Walsh SJ, Hanratty CG, Kumsars I, Stradins P, Steigen TK, Frobert O, Graham AN, Endresen PC, Corbascio M, Kajander O, Trivedi U, Hartikainen J, Anttila V, Hildick-Smith D, Thuesen L, Christiansen EH, investigators Ns, (2016) Percutaneous coronary angioplasty versus coronary artery bypass grafting in treatment of unprotected left main stenosis (NOBLE): a prospective, randomised, open-label, noninferiority trial. Lancet 388:2743-2752. https://doi.org/10.1016/ S0140-6736(16)32052-9

15. Morice MC, Serruys PW, Kappetein AP, Feldman TE, Stahle E, Colombo A, Mack MJ, Holmes DR, Choi JW, Ruzyllo W, Religa G, Huang J, Roy K, Dawkins KD, Mohr F (2014) Five-year outcomes in patients with left main disease treated with either percutaneous coronary intervention or coronary artery bypass grafting in the synergy between percutaneous coronary intervention with taxus and cardiac surgery trial. Circulation 129:2388-2394. https://doi.org/10.1161/circulationaha.113.006689

16. Neumann FJ, Sousa-Uva M, Ahlsson A, Alfonso F, Banning AP, Benedetto U, Byrne RA, Collet JP, Falk V, Head SJ, Juni P, Kastrati A, Koller A, Kristensen SD, Niebauer J, Richter DJ, Seferovic PM, Sibbing D, Stefanini GG, Windecker S, Yadav R, Zembala MO (2018) 2018 ESC/EACTS Guidelines on myocardial revascularization. Kardiol Pol 76:1585-1664. https://doi.org/10.5603/ KP.2018.0228

17. Park SJ, Kim YH, Park DW, Yun SC, Ahn JM, Song HG, Lee JY, Kim WJ, Kang SJ, Lee SW, Lee CW, Park SW, Chung CH, Lee JW, Lim DS, Rha SW, Lee SG, Gwon HC, Kim HS, Chae 
IH, Jang Y, Jeong MH, Tahk SJ, Seung KB (2011) Randomized trial of stents versus bypass surgery for left main coronary artery disease. N Engl J Med 364:1718-1727. https://doi.org/10.1056/ NEJMoa1100452

18. Passamani E, Davis KB, Gillespie MJ, Killip T (1985) A randomized trial of coronary artery bypass surgery. Survival of patients with a low ejection fraction. N Engl J Med 312:16651671. https://doi.org/10.1056/NEJM198506273122603

19. Patel MR, Calhoon JH, Dehmer GJ, Grantham JA, Maddox TM, Maron DJ, Smith PK (2017) ACC/AATS/AHA/ASE/ASNC/ SCAI/SCCT/STS 2017 appropriate use criteria for coronary revascularization in patients with stable ischemic heart disease: a report of the American College of Cardiology Appropriate Use Criteria Task Force, American Association for Thoracic Surgery, American Heart Association, American Society of Echocardiography, American Society of Nuclear Cardiology, Society for Cardiovascular Angiography and Interventions, Society of Cardiovascular Computed Tomography, and Society of Thoracic Surgeons. J Am Coll Cardiol 69:2212-2241. https://doi.org/10.1016/j.jacc.2017. 02.001

20. Reinohl J, Kaier K, Reinecke H, Schmoor C, Frankenstein L, Vach W, Cribier A, Beyersdorf F, Bode C, Zehender M (2015) Effect of availability of transcatheter aortic-valve replacement on clinical practice. N Engl J Med 373:2438-2447. https://doi.org/10.1056/ NEJMoa1500893

21. Sigwart U (2017) The stent story: how it all started. Eur Heart J 38:2171-2172. https://doi.org/10.1093/eurheartj/ehx339

22. Stachon P, Kaier K, Zirlik A, Bothe W, Heidt T, Zehender M, Bode C, von Zur MC (2019) Risk-adjusted comparison of inhospital outcomes of transcatheter and surgical aortic valve replacement. J Am Heart Assoc 8:e011504. https://doi.org/10. 1161/JAHA.118.011504

23. Stone GW, Kappetein AP, Sabik JF, Pocock SJ, Morice MC, Puskas J, Kandzari DE, Karmpaliotis D, Brown WM 3rd, Lembo NJ, Banning A, Merkely B, Horkay F, Boonstra PW, van Boven AJ, Ungi I, Bogats G, Mansour S, Noiseux N, Sabate M, Pomar J, Hickey M, Gershlick A, Buszman PE, Bochenek A, Schampaert
E, Page P, Modolo R, Gregson J, Simonton CA, Mehran R, Kosmidou I, Genereux P, Crowley A, Dressler O, Serruys PW, Investigators ET (2019) Five-year outcomes after PCI or CABG for left main coronary disease. N Engl J Med 381:1820-1830. https://doi. org/10.1056/NEJMoa1909406

24. Stone GW, Sabik JF, Serruys PW, Simonton CA, Genereux P, Puskas J, Kandzari DE, Morice MC, Lembo N, Brown WM 3rd, Taggart DP, Banning A, Merkely B, Horkay F, Boonstra PW, van Boven AJ, Ungi I, Bogats G, Mansour S, Noiseux N, Sabate M, Pomar J, Hickey M, Gershlick A, Buszman P, Bochenek A, Schampaert E, Page P, Dressler O, Kosmidou I, Mehran R, Pocock SJ, Kappetein AP, Investigators ET (2016) Everolimus-eluting stents or bypass surgery for left main coronary artery disease. $\mathrm{N}$ Engl J Med 375:2223-2235. https://doi.org/10.1056/NEJMoa1610 227

25. Suddock JT, Crookston KP (2020) Transfusion reactions. StatPearls, Treasure Island

26. Thuijs D, Kappetein AP, Serruys PW, Mohr FW, Morice MC, Mack MJ, Holmes DR Jr, Curzen N, Davierwala P, Noack T, Milojevic M, Dawkins KD, da Costa BR, Juni P, Head SJ, Investigators SES (2019) Percutaneous coronary intervention versus coronary artery bypass grafting in patients with three-vessel or left main coronary artery disease: 10-year follow-up of the multicentre randomised controlled SYNTAX trial. Lancet 394:1325-1334. https://doi.org/10.1016/S0140-6736(19)31997-X

27. Veterans Administration Coronary Artery Bypass Surgery Cooperative Study G (1984) Eleven-year survival in the Veterans Administration randomized trial of coronary bypass surgery for stable angina. N Engl J Med 311:1333-1339. https://doi.org/10. 1056/NEJM198411223112102

28. Yusuf S, Zucker D, Peduzzi P, Fisher LD, Takaro T, Kennedy JW, Davis K, Killip T, Passamani E, Norris R et al (1994) Effect of coronary artery bypass graft surgery on survival: overview of 10-year results from randomised trials by the Coronary Artery Bypass Graft Surgery Trialists Collaboration. Lancet 344:563570. https://doi.org/10.1016/s0140-6736(94)91963-1 